\title{
The Scientific Basis for Modern Physical Therapy
}

\author{
Charles N. Cornell, MD
}

Received: 7 August 2019/Accepted: 7 August 2019/Published online: 3 September 2019

(C) Hospital for Special Surgery 2019

Welcome to volume 15 , issue 3 , of HSS Journal®. In this issue, we present a special section that provides our readership the opportunity to explore the efforts by our physical therapy (PT) colleagues to explore the scientific basis of modern physical therapy practice. I direct you to the guest editorial by JeMe Cioppa-Mosca, MBA, who is the vice president of Rehabilitation at Hospital for Special Surgery (HSS). Her editorial provides a brief overview of the history of PT, in general and at HSS, and she introduces her colleagues who have contributed to this issue. In helping to put this special issue together, I was rewarded to discover how our PT colleagues are endeavoring to apply basic research

Electronic supplementary material The online version of this article (https://doi.org/10.1007/s11420-019-09719-6) contains supplementary material, which is available to authorized users.

C. N. Cornell, MD $(\bowtie)$

Hospital for Special Surgery,

535 East 70th Street,

New York, NY 10021, USA

e-mail: cornellc@hss.edu

C. N. Cornell, MD

Weill Cornell Medicine,

1300 York Avenue,

New York, NY 10065, USA principles to develop new approaches to their practice, as well as to apply the promising new technologies that are becoming available for both physical assessment and measurement. I am sure you will find these reports interesting and enlightening.

We also offer continuing medical education credit for an article by Schumaier and colleagues that explores the process of clinical decision-making when approaching management of rotator cuff tears and two articles addressing current topics in total joint replacement.

I am grateful to Cioppa-Mosca and her colleagues for helping to broaden the scope of our journal. I hope you enjoy learning of the effort our PT colleagues are applying to develop an evidence basis for their approach to care.

\section{Compliance with Ethical Standards}

Conflict of Interest: Charles N. Cornell, MD, reports personal fees from Exactech, Inc., outside the submitted work.

Human/Animal Rights: N/A

Informed Consent: N/A

Required Author Forms Disclosure forms provided by the authors are available with the online version of this article. 